\title{
BOND EFFICACY AND MORPHOLOGICAL INTERFACE OF SOLVENT FREE AND SOLVENT CONTAINING SELF ETCH ADHESIVES TO DENTIN
}

\author{
D.M. Amin ${ }^{*}$, A.I. Abdalla ** and H.Y. El-Sayed ${ }^{* *}$
}

\begin{abstract}
The aim was to measure the microshear bond strength of composite resin bonded to dentin by one solvent free self-etch, Bond-1 SF and two solvent containing adhesives, Futurabond DC and Adper Easy One and study the resin-dentin morphological interface by scanning electron microscope.
\end{abstract}

Materials and methods: 30 caries free third molars were used to prepare specimens of dentin surfaces. The adhesives were applied on dentin surfaces according to the manufacturer's instructions then Grandio-SO Composite resin was condensed through a polyethylene tube with a $0.7 \mathrm{~mm}$ internal diameter and $0.9 \mathrm{~mm}$ height attached firmly to dentin surfaces and light cured. The bonded specimens were stored in distilled water at $37^{\circ} \mathrm{C}$ for $24 \mathrm{~h}$ before being tested. All specimens were thermocycled in water baths held at $5^{\circ} \mathrm{c}$ and $55^{\circ} \mathrm{c}$ with a dwell time of 1 min each for 5000 cycles. The microshear bond strength was measured by using universal testing machine at cross head speed of $0.5 \mathrm{~mm} / \mathrm{min}$. To evaluate the resin dentin interface, 15 dentin slices were prepared, with five slices for each adhesive, a resin composite with each adhesive were placed $2 \mathrm{~mm}$ thick to form composite core. The segments were sectioned longitudinally and prepared to be examined under scanning electron microscope.

Result: Adper Easy One solvent containing adhesive recorded the highest mean value of bond strength followed by Bond-1 solvent free, while Futurabond DC solvent containing recorded the lowest mean value.

KEYWARDS: Self-Etch Adhesives, Solvent free and solvent containing adhesives, Microshear bond strength, Dentin.

\section{INTRODUCTION}

Adhesive systems are widely used in dental practice by definition they are responsible for establishing the bonding between restorative material and dental tissues ${ }^{1}$. According to the number of steps of use, they can be classified into

* Ministry of Health, Egypt

** Operative Dentistry. Faculty of Dentistry - Tanta University, Egypt 
one, two or three steps, depending on the way of procedure and number of bottles ${ }^{2}$.

Van Meerbeek et al.,(2001) ${ }^{3}$ classified contemporary adhesive systems into etch and rinse adhesive and self-etch adhesive. Etch and Rinse adhesive involves at least two steps and, in its most conventional form, three steps with successive application of the "conditioner" or "acid etchant" that is rinsed off. This conditioning step is followed by priming step in which the "primer" or "adhesion promoting agent" is applied, and eventually application of the actual "bonding agent" or "adhesive resin".

The simplified two-step version combines the second and third steps but still follows a separate "etch \& rinse" phase ${ }^{2}$. After conditioning step, adhesion promoting monomers are applied in one step to penetrate the exposed collagen network ${ }^{4}$

The priming step in three-step etch-and-rinse adhesive should ensure sufficient wetting of the exposed collagen fibrils and remove remaining water, thereby preparing dentin for adhesive resin infiltration. A primer solution is a mixture of specific monomers with hydrophilic properties to be compatible with humid environments dissolved in organic solvents such as ethanol or acetone or in water. HEMA (2-Hydroxyethyl methacrylate) is an important monomer that is very frequently added to these primer solutions. Due to its low molecular weight and hydrophilic nature, HEMA promotes resin infiltration into and re-expansion of the collagen network, thereby improving bond strength of the adhesive ${ }^{4}$

The adhesive resin "bonding agent" is a solvent-free, filled or unfilled (containing filler particles) solution containing mainly hydrophobic monomer. The main function of this adhesive resin is to fill up the interfibrillar spaces leftbetween the collagen fibrils. Upon curing and polymerization of these monomers, a hybrid layer and resin tags are created that provide adhesive bonding components and combined into one solution that should fulfill both function ${ }^{4}$. However, filled adhesives have higher bond strength than unfilled ${ }^{5}$. Recently, allin-one adhesive or one step self-etch adhesives which combine etchant, primer and bonding resin into one solution ${ }^{6}$. Different solvents presented in primer components or in simplified bonding agents are responsible for either carrying excess water out or infiltrating resin monomers into interfibrillar dentin ${ }^{7}$. As solvent is necessary to provide a proper infiltration of the resin monomers into demineralized collagen matrix, the bonding process still depend on its capacity ${ }^{8}$

Benefits offered by solvents rely on their properties of improving substrate wetting, aiding to impede the collagen fibrils collapse or to stiffen them ${ }^{7}$. However, solvents must be eliminated after having completed their function because it has been demonstrated that residual solvent can lead to deterioration of the adhesive interface ${ }^{9}$ by interfering with resin polymerization ${ }^{10}$ and decreasing mechanical properties ${ }^{8}$. Recently, a new solvent-free, self-etching, single-bottled system has been introduced. This adhesive uses a proprietary formula that eliminates the need for commonly used solvents such as acetone, alcohol, and water, and not only reduces the number of application steps, but removes the ambiguity of air-volatilizing residual solvents prior to light-curing. Because residual solvents can reduce bond strengths and disrupt the hermetic seal needed to eliminate water transportation from the underlying dentin ${ }^{11}$. The aim of the present study was to evaluate the microshear bond strength of one solvent free adhesive system (Bond-1SF) and two solvent containing adhesive systems (Futurabond DC. and Adper Easy One) to dentin and study the resin-dentin interface by scanning electron microscope to detect hybrid layer and resin tags formation.

The null hypothesis tested was solvent free and solvent containing adhesives have no direct effect on the bond strength. 
TABLE (1) Composition and manufacturer"s instructions of self etching; solvent containing and solvent free adhesive systems used in the present study.

\begin{tabular}{|c|c|c|}
\hline Tested materials & Composition & Manufacturer's instruction for use \\
\hline $\begin{array}{l}\text { Bond-1 SF solvent free, one step self } \\
\text { etch adhesive. }\end{array}$ & $\begin{array}{l}\text { Mixture of UDMA, TEGDMA, HEMA \& } \\
\text { 4-MEfA resins, silane-treated bariumborosilicate glasses, } \\
\text { silica with initiator, stabilizers and UV absorber, organic } \\
\text { and/or inorganic pigments, and opacities }\end{array}$ & $\begin{array}{l}\text { - Dip applicator and spread evenly. } \\
\text { - rub for } 20 \mathrm{~s} \text {, } \\
\text { - light cured for } 10 \mathrm{~s}\end{array}$ \\
\hline $\begin{array}{l}\text { Futurabond DC Solvent containing, } \\
\text { one step self etch adhesive. }\end{array}$ & $\begin{array}{l}\text { Liquid A: water, ethanol, silicon dioxide Liquid B: acid } \\
\text { modified methacrylate (methacrylate ester), HEMA, Cam- } \\
\text { phroquinone }\end{array}$ & $\begin{array}{l}\text { - Dispense one drop of liquid A and other of B into the well } \\
\text { and mix for } 5 \mathrm{~s} \\
\text { - apply adhesive with rubbing motion for } 15 \mathrm{~s} \text { - gentle air dry } \\
\text { for } 5 \mathrm{~s} \text { - light cure for } 20 \mathrm{~s} \\
\text { - Rubbing the bond gently for } 20 \mathrm{~s} \text {. } \\
\text { - gentle air drying for } 5 \mathrm{~s} \\
\text { - light cured for } 10 \mathrm{~s} \text {. }\end{array}$ \\
\hline $\begin{array}{l}\text { Adper Easy One Solvent containing, } \\
\text { one step self etch adhesive. }\end{array}$ & $\begin{array}{l}\text { HEMA, BIS-GMA, methacrylate phosphoric ester, 1,6 } \\
\text { hexanediol dimethacrylate, methacrylate functionalized, } \\
\text { polyalkenoic acid, bonded silica nonofiller, ethanol, water }\end{array}$ & $\begin{array}{l}\text { One mm plastic cylindrical molds were filled with resin com- } \\
\text { posite and attached to the conditioned dentin surfaces and } \\
\text { cured for } 40 \mathrm{~s}\end{array}$ \\
\hline Grandio-SO Composit resin, & $\begin{array}{l}\text { - Filler: glass ceramic filler, functionalized silicon dioxide } \\
\text { nano-particles, } \\
\text { - iron oxide and titanium dioxide pigments } \\
\text { - resin: BIS-GMA, BISEMA, TEGDMA } \\
\text { - carnphroquinone photo-catalyst } \\
\text { - hydroxytoluene (BHT) stabilizer. }\end{array}$ & \\
\hline
\end{tabular}

\section{MATERIALS}

Materials that have been used in this study illustrated in table (1) including the following:

a) One solvent free adhesive system: Bond-1 SF self-etch adhesive

b) Two solvent containing self-etch adhesives:

1- Futurabond DC

2- Adper Easy One

c) Composite resin restoration, shade 3 .

\section{METHODS}

\section{3-1 Specimen preparation}

Thirty freshly extracted caries free, unrestored human third molars from patients aged 20-30 years old were collected and stored in distilled water containing $0.2 \%$ thymol antiseptic solution for $48 \mathrm{~h}$ at $37^{\circ} \mathrm{C}$ immediately after extraction, were selected for the study ${ }^{12}$. A written consent was taken from these patients after the study was approved by the Ethics Committee of Tanta University to ensure their agreement to use their teeth in the current study. The teeth were cleaned of debris using a rubber cup, pumice and a low speed hand piece.
The teeth were mounted vertically in cold curing acrylic resin $2 \mathrm{~mm}$ below cemento-enamel junction,using plastic circular molds. Superficial coronal dentin was exposed by horizontal trimming the occlusal surface of each tooth crown under running water. After trimming, the resulting surfaces were be flattened and finished using 600 grit silicon carbide papers to create a standardized smear layer ${ }^{13}$. The prepared specimens were assigned to three groups of ten (10) each according to the tested adhesive system used.

Group 1: using Bond-1 SF solvent free one step self etch adhesive

Group 2: using Futurabond DC, solvent containing one step self etch adhesive

Group 3: using Adper Easy, solvent containing one step self etch adhesive

Each adhesive system was applied according to the manufacturer's instructions over exposed dentin surface in each group as shown in Table 1. Polyethylene tubes with $0.7 \mathrm{~mm}$ internal diameter and $0.9 \mathrm{~mm}$ of height were firmly attached to the conditioned dentin surfaces and filled with resin composite and then cured for $40 \mathrm{~s}$ using a 
conventional halogen light-curing at a light intensity of $500 \mathrm{~mW} / \mathrm{cm} 2$ at zero distance. The specimens were subjected to 5000 thermocycling* $\left(5^{\circ} \mathrm{c}\right.$ to $55^{\circ} \mathrm{c}$ ) with 20 seconds dwell time and 5-10 seconds transfer time ${ }^{14}$. All specimens were subjected to micro shear bond strength (mSBS) using universal testing machine** with a load cell of $5 \mathrm{kN}$ at cross head speed of $0.5 \mathrm{~mm} / \mathrm{min}$, until failure occurred and data were recorded using computer software. A $0.2 \mathrm{~mm}$ diameter stainless steel orthodontic wire will be looped flush between the load cell projection and the resin cylinder making contact with the lower half-circle of the cylinder and touching the tooth surface. Care was taken to keep the composite cylinder in line with the center of the load cell and to keep the wire loop parallel to the load cell movement direction and to the bonded surface in order to maintain a shear stress orientation at the bonding interface. The maximum load at the time of failure was recorded and the bond strength expressed in Mega Pascal (MPa) was calculated from the cross-sectional area of the resin composite cylinder according to the following equation: $\boldsymbol{\tau}=\mathbf{P} /$ $\pi \mathbf{r}^{2}$ where $\boldsymbol{\tau}$ is the bond strength (MPa), $\mathbf{P}$ is the load at failure (N), $\mathbf{P}$ is 3.14 and $\mathbf{r}$ is the radius of a composite micro-cylinder ( $\mathrm{mm}$ ).

Values of micro-shear bond strength data were be calculated and statistically analyzed using one way ANOVA test.

Fifteen dentin slices were prepared, with five slices for each adhesive. After adhesive application according to manufacturer's instruction, a resin composite was placed $2 \mathrm{~mm}$ thick to form a composite core. The specimens were sectioned longitudinally into two half. The fracture surface of each half was polished with an increased grit of silicon paper, under running water.
1. In one half of the dentin slice, the interface between composite and dentin was etched with $37 \%$ phosphoric acid for 30 seconds, rinsed with water spray, depolarized with $2 \%$ sodium hypochlorite for 60 seconds, and then rinsed with water to detect resin tags penetration within dentinal tubules and hybrid layer thickness ${ }^{15}$.

2. The other half of dentin specimen was kept in $30 \%$ HCL solution for 2 days to completely remove the dental tissues to detect resin tags and hybrid layer thickness without dentin. All specimens were examined under scanning electron microscope. ${ }^{* * *}$

\section{RESULTS}

The descriptive statistics for the micro-shear bond strength of different adhesive systems, Bond-1 SF solvent free one step self etch adhesive, Futurabond DC and Adper Easy, solvent containing one step self etch adhesives, It was found that, the highest mean value was recorded for group Adper Easy One solvent containing adhesive system, recording 18.429 $\mathrm{MPa} \pm 2.087$ followed by group (Bond-1 SF) solvent free adhesive system, recording $15.832 \mathrm{MPa}$ \pm 1.668 , while the lowest mean bond strength value $11.923 \mathrm{MPa} \pm 1.680$ was found at group Futurabond DC solvent containing adhesive system.

ANOVA test was used to compare the tested groups at a level of significance $\mathrm{p}=0.001(\mathrm{p}<0.05)$ and reported a statistical significant difference.

\footnotetext{
* Petrotest Bath used for temperature 55oc, Julabo Bath used for temperature 5oc

** NEXYGEM, model LRX-plus; Lloyd instruments ltd, Fareham, Uk

*** JSm-5300 Scanning Microscope, JEOl, Peabody, MA, USA
} 
TABLE (2) Mean values of the mean microshear bond strength values of the three tested groups

\begin{tabular}{|c|c|c|c|c|c|c|c|c|}
\hline \multirow{2}{*}{ Groups } & \multicolumn{6}{|c|}{ Microshear bond strength } & \multicolumn{3}{c|}{ ANOVA } \\
\cline { 2 - 7 } & \multicolumn{3}{|c|}{ Range } & Mean & \pm & SD & F & P-value \\
\hline Futura-B & 10.140 & - & 15.446 & 11.923 & \pm & 1.680 & \multirow{2}{*}{32.297} & $<0.001^{*}$ \\
\hline Adper-EO & 14.993 & - & 22.058 & 18.429 & \pm & 2.087 & & \\
\hline Bond-1 SF & 14.018 & - & 19.207 & 15.831 & \pm & 1.668 & & \\
\hline
\end{tabular}

TABLE (3) Comparison of total microshear bond strength mean values as function of adhesive type

\begin{tabular}{|c|c|c|c|c|c|c|c|c|}
\hline \multirow{2}{*}{ Types of adhesives } & \multicolumn{6}{|c|}{ Microshear bond strength according types of adhesive } & \multicolumn{2}{|c|}{ T-Test } \\
\hline & \multicolumn{3}{|c|}{ Range } & Mean & \pm & SD & $\mathbf{T}$ & P-value \\
\hline Solvent containing & 10.140 & - & 22.058 & 15.176 & \pm & 3.813 & \multirow{2}{*}{-0.516} & \multirow{2}{*}{0.610} \\
\hline Solvent free & 14.018 & - & 19.207 & 15.831 & \pm & 1.668 & & \\
\hline
\end{tabular}

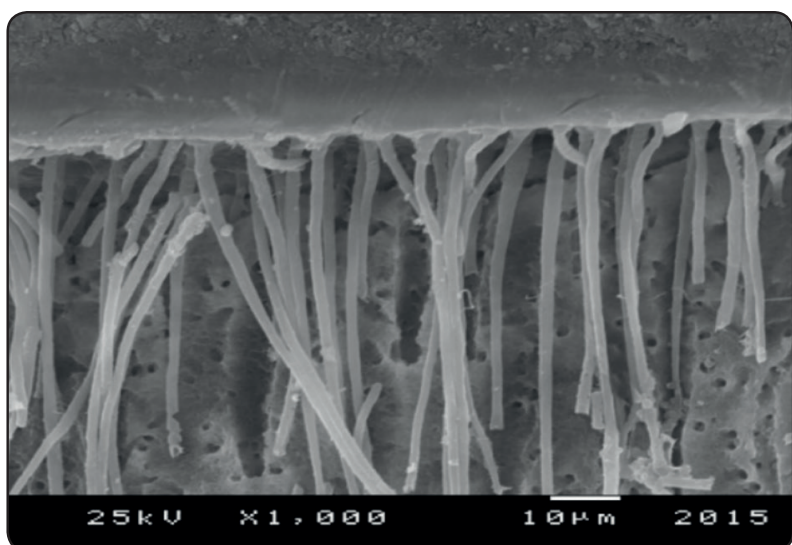

Fig (1) SEM image of resin-dentin interface from group II Adper Easy One, showing continuous well developed hybrid layer with numerous long and slightly thick resin tags

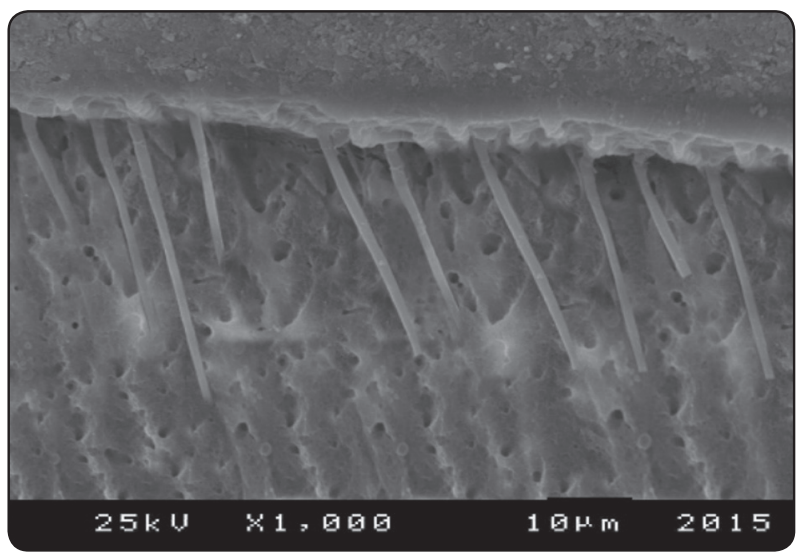

Fig (3) SEM image of resin-dentin interface from group I Futurabond DC , showing discontinuity of hybrid layer with few short resin tags

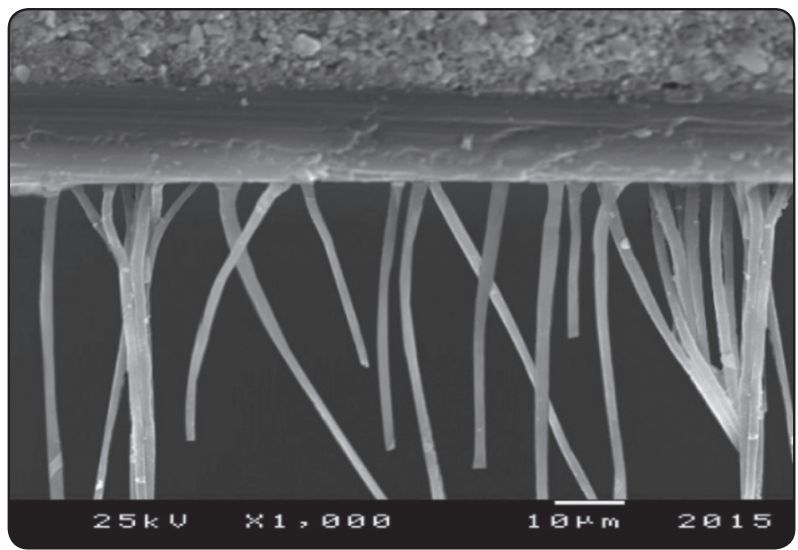

Fig (2) SEM image of resin-dentin interface from group II Adper Easy One, after keeping the dentin slices in $30 \%$ HCL Solution for 2 days, showing anumerous long and slightly thick resin tags

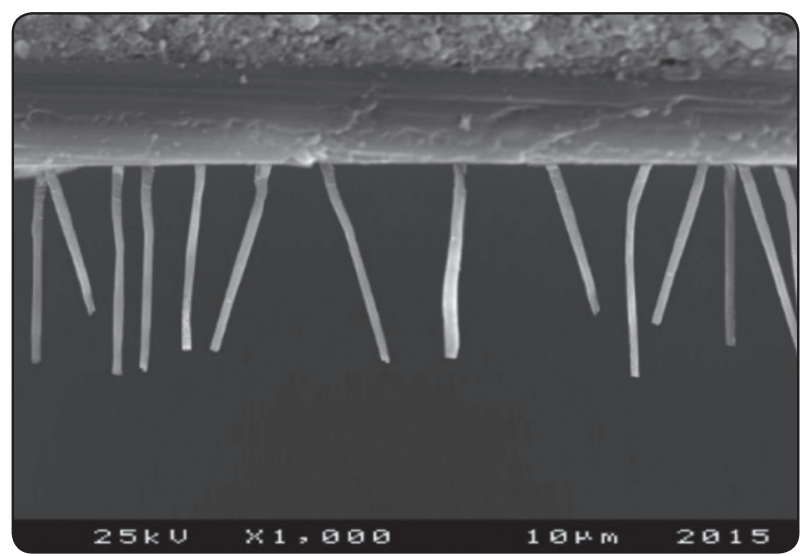

Fig (4) SEM image of resin -dentin interface from group I Futurabond DC , after keeping the dentin slices in $30 \%$ HCL solution for 2 days, showing few short resin tags 


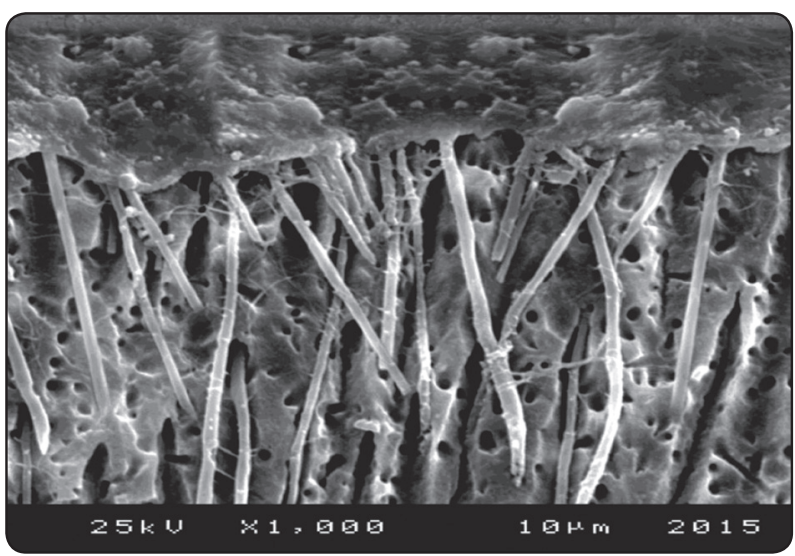

Fig (5) SEM image of resin-dentin interface from group III Bond-1 SF, showing continues and discontinues of hybrid layer with few hesitated long resin tags

\section{DISCUSSION}

Dentin bonding systems for resin composite restorations have been widely used over the past few decades. The latest advancement in adhesion technology is the one step self-etch adhesive system, which combine etching, priming, and bonding into single procedure. Generally, one-step self-etch consist of ionic resin monomers with phosphate or carboxylic functional groups, hydrophilic monomers (e.g HEMA), hydrophobic monomers (e.g BIS-GMA, UDMA), solvents (water and organic solvents like ethanol or acetone), fillers, and initiators.The addition of solvents to resins is indispensable to the composition of adhesives that need to bond to dentin. The wet nature of dentin only allows good wetting when a hydrophilic bonding is applied. ${ }^{16}$ By adding hydrophilic monomers on one hand, and a solvent on the other, the wetting behavior of the adhesive is improved. ${ }^{17}$ In the present study microshear bond strength testing was used an ultra-small bonding areas which in believed to have fewer defects occurring at the resin-dentin interface. Moreover, several authors observed higher microshear bond strengths than conventional shear bond strengths because of the smaller surface area. ${ }^{18,19}$

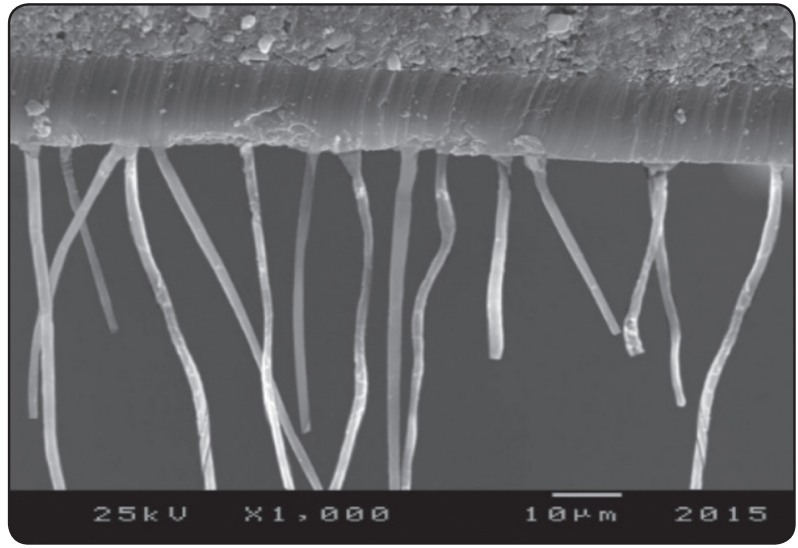

Fig (6) SEM image of resin-dentin interface from group III Bond-1 SF after keeping in 30\% HCL solution for 2 days, showing continuous of hybrid layer with few thin and long resin tags

Scanning electron microscope was used in this study to examine the morphological characteristics of hybrid layer and resin tags of the bonded dentin/composite interface. ${ }^{20}$ Van Meerbeek et al., $2003^{21}$ reported that the efficiency of bonding to dentin depends mostly on micromechanical retention promoted by resin infiltration in partially demineralized dentin with consequent hybrid layer and resin tags formation. In the current study, Adper Easy One (solvent containing $\mathrm{pH}=2.3$ considering belong to mild adhesives) recorded the highest microshear values (18.429 $\mathrm{MPa})$, which can be confirmed by SEM images fig $(1,2)$ which showing mostly continuous hybrid layer with numerous long resin tags. This result was explained and agreed with De Munck et al, $2005^{22}$ who found that the bonding effectiveness of mild self-etch adhesives may result from a combined micromechanical and chemical interaction with tooth substrate, the chemical component may able to compensate for the reduced bonding effectiveness from decreased micromechanical interlocking. The combination of mild self-etch adhesives and micromechanical and chemical bonding may increase the longevity of the restorations and be more stable over time than the bonding interface of a total-etch adhesives, as the chemical interaction may result in bonds that 
better resist hydrolytic degradation. On the other hand, Senawongse et al. ${ }^{23}$ and Sattabanasuk et al. ${ }^{24}$ disagreed with our result who reported that mild self-etch systems are able to partially remove the smear layer and penetrate the dentinal surface, creating a less pronounced resin tag formation and hybrid layers. Also the current result revealed that Futurabond DC (solvent containing one step self-etch adhesive $\mathrm{pH}=1.4$ considering belong to intermediate strong adhesives) recorded the lowest microshear bond strength value (11.923 MPa), which can be confirmed by SEM images fig $(3,4)$ showing mostly discontinuous hybrid layer with few short resin tags. The finding in our study are in agreement with Inoue and others in $2001{ }^{25}$, result who stated that, the bonding mechanism of intermediary strong adhesives resembles that of total-etch adhesives, they produced lower bond strengths to dentin. This may be advocated to the fact that these adhesive are not separately rinsed off, so the unreacted acid groups of the unpolymerized monomers, remaining after light curing at the oxygen inhibited layer, attack the polymerization initiation system of composite material. As well as, lack of sufficiently thick and uniform resin layer that stabilizes the hybrid layer may also contribute to the lower bond strength value.

Moreover, in the current study Bond-1 SF (solvent free, one step self-etch adhesive system have $\mathrm{pH}=3-4$ considering belong to ultra-mild), recorded lower statistically significant bond strength than Adper Easy One solvent containing (15.831 $\mathrm{MPa}, 18.429 \mathrm{MPa}$ respectively), which can be confirmed by SEM images fig. $(5,6)$ which showing mostly continuous hybrid layer but with few long resin tags. These result agreed with Chopra et al., $2009^{26}$, who reported that Bond-1 SF solvent-free self-etch adhesive does not have conventional cosolvents in its chemical composition, which results in a thicker adhesive layer and this assumed to increase the hydrophilic content in Bond-1 SF in comparison to solvent containing adhesive and as a result of their high hydrophilicity, these adhesives behave as semi permeable membrane allowing more fluids to pass through in comparison to solvent containing adhesive, which seems to lead to lower bond strength.

\section{CONCLUSIONS}

(1) Adper Easy One solvent containing one step self-etch performed the best microshear bond strength to dentin than the Bond-1 SF solvent free self-etch and Futurabond DC solvent containing self-etch adhesive and the differences were statistically significant.

(2) Totally, adhesive system either solvent containing or solvent free has no statistically significant direct effect on the bond strength.

\section{REFERENCES}

1. Carvalho, R. M. Sistemasadesivos: fundamentos para aplicacao clinicao. Biodonto., 2004 2:1-86. (Quoted from Adhesive systems: Considerations About Solvents).

2. Van Landuyt, K.; Lambrechts, P.\&Vanherle, G. Budnocore memorial lecture. Adhesion to enamel and dentin: current status and fujwechatfenges. Oper. Dent. 2003, 28:215-35.

3. Van Meerbeek B, (none S, Perdigao J, Lambrechts P, Vanherle G. Enamel and Dentin adhesion. In: Summitt JB, Robbins JW, Schwartz RS, ads. Fundamental of Operative Dentistry, 2 nd ed. Quintessence Book: 2001 178-235.

4. Prdigao J \& Swift J): sturdevanf s Art \& Science of Operative Dentistry 5th ed. Mosby CO, St. Louis, London.2006, Pp 251-252.

5. Armstrong SR, Keller JC, Boyer DB. The influence of water storage and C-Factor on the dentin-resin composite microtensile bond strength and debond pathway utilizing a filled and unfilled adhesive resin. Dent Mater 2001; $17: 268-276$

6. Frankenberger R, Perdigao J, Rosa BT, Lopes M. "Nobottle" vs "multi-bottle" dentin adhesives - a microtensile bond strength and morphological study. Dent Mater. 2001, 17:373-80.

7. Maciel KT, Carvalho RM, Ringle RD, preston CD, Russell CM, pashley DH. The effects of acetone, ethanol, HEMA, and air on the stiffness of human decalcified dentin matrix. J Dent Res. 1996, 75:1851-1858. 
8. Reis AF, Oliveria MT, Giannini M, De Goes MF, Rueggerberg FA. The effect of organic solvent on onebottle adhesives bond strength to enamel and dentin. Oper Dent 2003, 28:700-706.

9. Tay FR, Pashley DH, Garcia-Godoy F, Yiu CK. Singlestep, self-etch adhesives behave as permeable membranes after polymerization. Part II. Silver tracer penetration evidence. Am J Dent 2004, 17:315-322

10. Kanca III J. Resin bonding to wet substrate. I. Bonding to dentin.Quintessence Int. 1992, 23:39-42

11. Jia W, Jin S, Turcotte J. Breaking the" Generation" Gap. Inside Dentistry. 2010, $6: 2-5$

12. Praphasri R, Kadkao V and Rudee S. Shear bond strength of some sealant under saliva contamination. Southeast Asian J. 2011;42: 463-467

13. Sibel. Microtensile and microshear bond strength of an bacterial self-etching systems to primary tooth dentin. Eur J Dent 2008; 543-552

14. Antonson SA, Wanuck J, Antonson DE. Surface protection for newly erupting first molars. Compend of Cotin Educ Dent 2006;27:215-235

15. Opdam NJ, Feilzer AJ, Roeters JJ, Smale I. Class I occlusal composite resin restorations: in vivo post-operative sensitivity, wall adaptation, and microleakage. Am J Dent. 1998; 11:229-234

16. Watanabel LG, Marshall GW, Bedford DT and Mashell SJ. Influence of etching on shear bond strength of dentin adhesives J Dent Res. 1994 Abstract \#797 P. 205

17. Tay FR, Pashley DH. Water treeing- a potential mechanism for degradation of dentin adhesives. Am J Dent 2003; 16: 6-12
18. Zheng L, Preira PNR, Nakajima M, Sano H and Tagami J. Relationship between adhesive thickness and microtensile bond strength. Oper Dent 2001; 26: 97-104

19. Versluis A, Tantbirojin D, Douglas WH. Why do shear bond test pull out dentin? J Dent Res 1996;76: 1298-1307

20. Yousry MM. Effect of re-etching oxalate-occluded dentin and enamel on bonding effectiveness of etch-and-rinse. Adhesives J Adhes Dent 2012;14: 31-38

21. Van Meerbeek B, De Munck J, Yoshida Y, Inoue S, Vargas $\mathrm{M}$ et al. Buonocore memorial lecture. Adhesion to enamel and dentin. Current status and future challenges. Oper Dent 2003;28: 215-235

22. De Munck J, Vargas M, Iracki J, Van Landuyt K, Poitevin A, Lambrechts P, et al. One day bonding effectiveness of new self-etch adhesives to bur cut enamel and dentin . Oper Dent 2005; 49(1) 49 (Pub Med)

23. Senawongse P, Harnirattisai C, Shimada Y, Tagami J. Effective bond strength of current adhesive systems on deciduous and permenant dentin Oper Den 2004; 29:196-202

24. Sattabansuk V, Shimada Y, Tagami J. The bond of resin to different dentin surface characterstics. Oper Dent 2004: 29:333-341

25. Inoue S, Vargas MA, Abe Y, Yoshida Y, Lamberchts $P$, Vanherle G, Sano H and Van Meerbeek B. Microtensile bond strength of eleven contemporary adhesives to dentin J Adhes Dent 2001; 3: 237-245

26. Chopra V, Sharma H, Prasad SD. A comparative evaluation of the bonding efficacy of two-step vs all-in-one bonding agents. An in vitro study. J Conserv Dent 2009;12: 101-4 